\title{
Severity of Tomato Blossom-end Scarring is Determined by Plant Age at Induction
}

\author{
H.C. Wien'and A.D. Turner ${ }^{2}$ \\ Department of Fruit and Vegetable Science, Cornell University, Ithaca, NY 14853 \\ Additional index words. catfacing, fruit size, gibberellic acid, locule number, Lycopersicon esculentum
}

\begin{abstract}
Tomato plants were induced to produce fruit with abnormally large blossom-end scars (catfaces) by exposing them to 16/10C (day/night) for 2 weeks, starting at the six-leaf stage. Fruit of the second and third, but not the first, cluster showed catface symptoms. To identify the initial period of susceptibility to catfacing, 'Revolution' tomatoes were greenhouse-grown for 34,48 , or 62 days and induced to catface by a gibberellic acid $\left(\mathrm{GA}_{3}\right)$ foliar spray $(43 \mu \mathrm{M})$ when transplanted to the field. Catfacing was significantly increased by $\mathbf{G A}_{3}$ sprays $(23 \%$ vs. $11 \%$ of all fruit in $1989,22 \%$ vs. $\mathbf{8 \%}$ in 1990). There was a highly significant interaction between plant age and catfacing, with high levels for young and medium-aged, but lower levels for old $\mathrm{GA}_{3}$-treated transplants. The early-maturing 'Revolution' is susceptible to catfacing from $\approx 25$ to 60 days after sowing. Marketable yields were highest for young and medium-aged plants in 1989 and 1990, respectively. Old plants were checked in growth after being transplanted and produced lowest yields. Avoiding catfacing by using old transplants has doubtful practical value.
\end{abstract}

The formation of an abnormally large scar at the blossom end of tomatoes has been termed "catfacing" by growers and is responsible for considerable yield loss of fresh-market tomatoes in cool North American growing regions (Wien and Zhang, 1991). Catfacing under field conditions is caused by air temperatures of $\approx 17 / 10 \mathrm{C}$ (day/night) maintained for at least 1 week (Saito and Ito, 1971). We have shown recently that foliar sprays of gibberellic acid (GAS) can also induce the disorder (Wien and Zhang, 1991). This allows the disorder to be induced with precise timing, independent of the weather conditions that may exist in the field at the time.

Until recently, the stage of development at which plants are sensitive to catfacing and the time required after induction to express symptoms of the disorder have not been defined. Barten et al. (1992) found that under Florida conditions, flower buds were most sensitive to catfacing $\approx 19$ to 26 days before anthesis, but it is not clear if this period would also apply to the cooler conditions of New York. Information on the timing of susceptibility may help avoid the disorder. If most flower buds are already past the susceptible stage when the plants are subjected to inducing temperatures, few fruit would be affected. These experiments were conducted to pinpoint the susceptible stage for catfacing of individual flower clusters in temperatures typical of spring conditions in a temperate zone (i.e., New York).

\section{Materials and Methods}

Catface-induction experiment. 'Revolution' determinate tomato plants were started in a 21/16C (day/night) greenhouse in planter trays (no, 200 Todd; Speedling, Sun City, Fla.) with 80-ml cells filled with peat-vermiculite artificial soil mix. After being repotted to $10-\mathrm{cm}$-diameter $(475-\mathrm{ml})$ plastic pots filled with mix 30 days after sowing, plants were placed for 2 weeks in one of two growth chambers set either at $21 / 16$ or $16 / 10 \mathrm{C}$ with a $14-\mathrm{h}$ photoperiod. Thereafter, the plants were repotted to $23-\mathrm{cm}$-diameter (5.6-liter) plastic pots containing artificial soil mix and returned to the $21 / 16 \mathrm{C}$ greenhouse. Plants were pruned to retain only the main stem and the branch below the first inflorescence and tied

Received for publication 1 Feb. 1993. Accepted for publication 11 May 1993. The cost of publishing this paper was defrayed in part by the payment of page charges. Under postal regulations, this paper therefore must be hereby marked advertisement solely to indicate this fact.

${ }^{1}$ Professor.

${ }^{2}$ Graduate student. to stakes. Anthesis dates of the first three main-stem and the first two branch inflorescences were monitored at 2-day intervals. When the first fruit on these clusters reached mature-green stage, catfacing was evaluated on three fruit per cluster by measuring the maximum diameter of the blossom-end scar and expressing it as a proportion of the maximum fruit diameter (scar ratio). In addition, fruit were halved equatorially and the locules were counted. There were 10 plants per treatment, and the experiment had a completely randomized design during the grow-out period after the unreplicated temperature treatments.

Transplant-age experiments. In 1989 and 1990, 'Revolution' tomato seedlings were started in planter trays (no. 150 Todd; Speedling) with 36-ml cells at 2-week intervals for three consecutive plantings. The earliest-sown plants were transplanted to 1300$\mathrm{ml}$ pots 28 days after sowing (DAS). Medium-aged plants were transferred to $475-\mathrm{ml}$ pots 24 DAS. When transplanted to the field on 5 and 12 June (1989 and 1990 experiments, respectively), the plants in the three age groups were 62,48, and 34 days old.

The experiments were conducted on a Howard gravelly loam soil (loamy skeletal, mixed mesic, Glossoboric Hapludalf) fertilized with (in $\mathrm{kg} \cdot \mathrm{ha}^{-1}$ ) $118 \mathrm{~N}-52 \mathrm{P}-98 \mathrm{~K}$ broadcast before plowing and harrowing. To control weeds, a mixture of 4-amino-6-tertbutly-3-(methylthio)-as-triazin-5(4H)-one (metribuzin) and 2,6dinitro-N,N-dipropyl-4-(trifluoromethyl)benzenamine (trifluralin) was sprayed on the experimental area at rates of 0.06 and 0.84 $\mathrm{kg} \cdot \mathrm{ha}^{-1}$, respectively, and lightly incorporated. Plots consisted of single rows of 10 plants each spaced $152 \mathrm{~cm}$ apart with an in-row spacing of $61 \mathrm{~cm}$.

To induce catfacing, plants were treated with a foliar spray of $43 \mu \mathrm{M} \mathrm{GA}$, either just before (1989) or 2 days after (1990) transplanting. Plants in the control treatment were sprayed with tap water at the same time. The experiments had a randomized completeblock design with a factorial treatment design, with four replications.

Ripe fruit were harvested weekly and classified as marketable, nonmarketable (for causes other than catfacing), or catfaced. The latter category included all fruit that had blossom-end scars longer than $1 \mathrm{~cm}$. Statistical analysis of catfacing percentage was performed on the arcsin-transformed variable.

\section{Results and Discussion}

Catface-induction experiment. The 2-week cool-temperature treatment delayed anthesis of the first cluster by $\approx 1$ week (Fig. 1), 


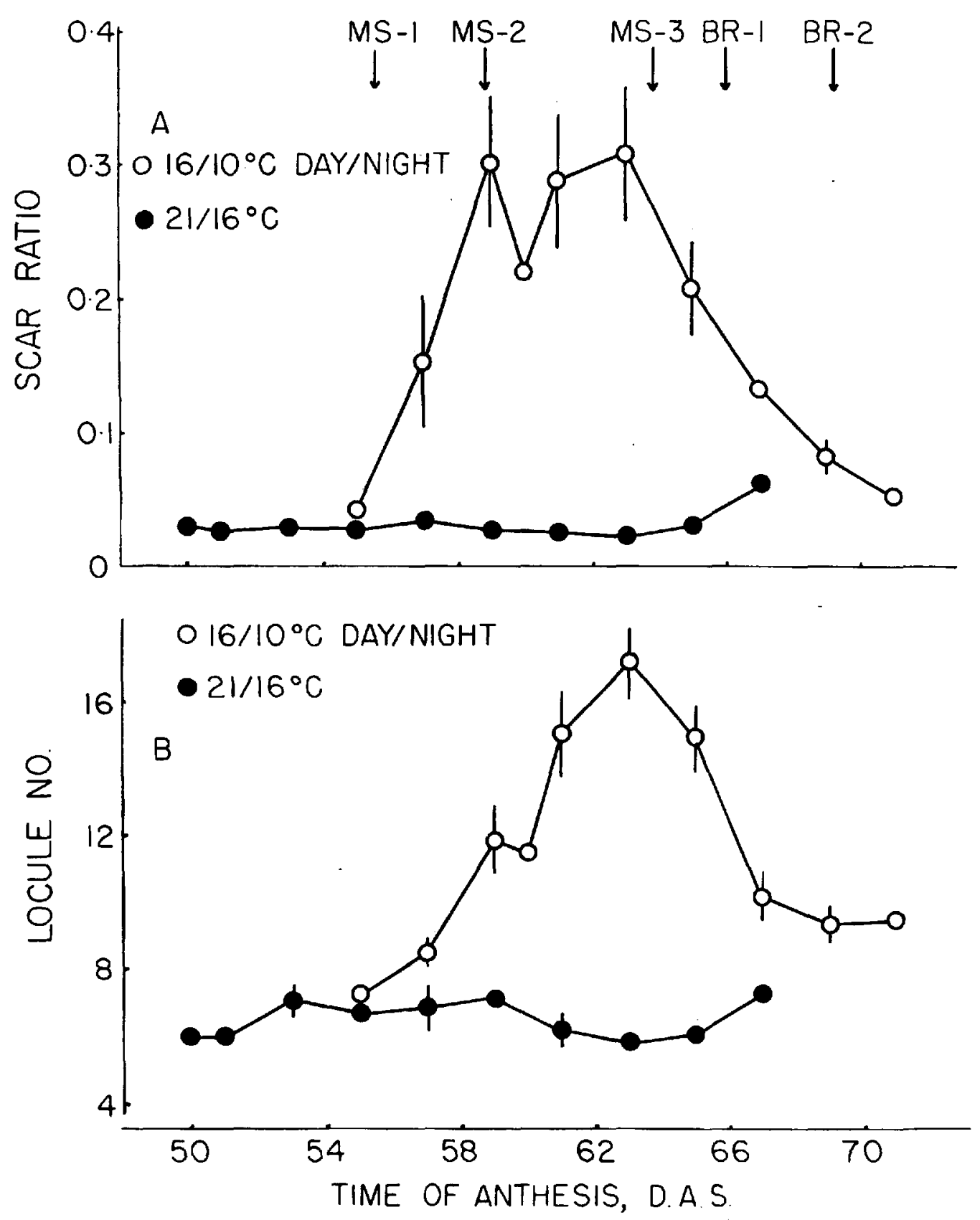

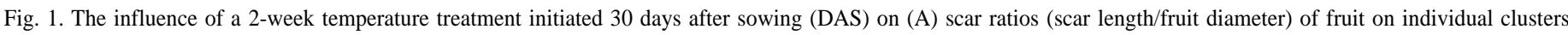
and (B) their corresponding locule numbers, plotted against cluster anthesis dates. Arrows mark the average anthesis dates of main-stem (MS) clusters 1 to 3 and clusters 1 and 2 on the primary branch (BR) for plants subjected to 16/10C day/night.

but had little effect on scar ratio or number of locules per fruit on that cluster. Clusters whose flowers reached anthesis 26 to 35 days after initiation of the cold treatment developed fruit with large blossom-end scars and increased locule number. It is likely that the first cluster's flower primordia, which were 25 days from anthesis at the time the cool temperature was initiated, had already developed past the susceptible stage.

Barten et al. (1992) found that tomato flower primordia were most susceptible to blossom-end scarring 16 days or more before anthesis. Since their plants were grown at high temperatures after catface induction (32/18 or $29 / 18$ compared to $21 / 16 \mathrm{C}$ in the present study), the discrepancy in cluster age at time of initial sensitivity is likely due to accelerated plant development from the sensitive stage to anthesis in the higher temperatures.

Transplant-age experiment. Treating the transplants with GA increased catfacing incidence in both years, but a greater percentage of fruit on young and medium-aged transplants were affected than on old ones (Fig. 2). The $\mathrm{GA}_{3} \times$ age interaction was highly significant. From the results of the catface induction experiment, we deduce that the young transplants must have had only the first one or two clusters developed past the susceptible stage at the time $\mathrm{GA}_{3}$ was applied. In the medium-aged transplants, all main-stem clusters and the first cluster on the primary branch would have been too old to be affected, while in the old transplants, most clusters producing yield were already formed when catfacing was induced. This is confirmed by the time course of yield production of catfaced and normal fruit (Fig. 3).

Early-maturing tomatoes grown under the climatic conditions of the northeastern United States were sensitive to catfacing at 34 and 48 DAS but not at 62 DAS. For cultivars of later maturity and 


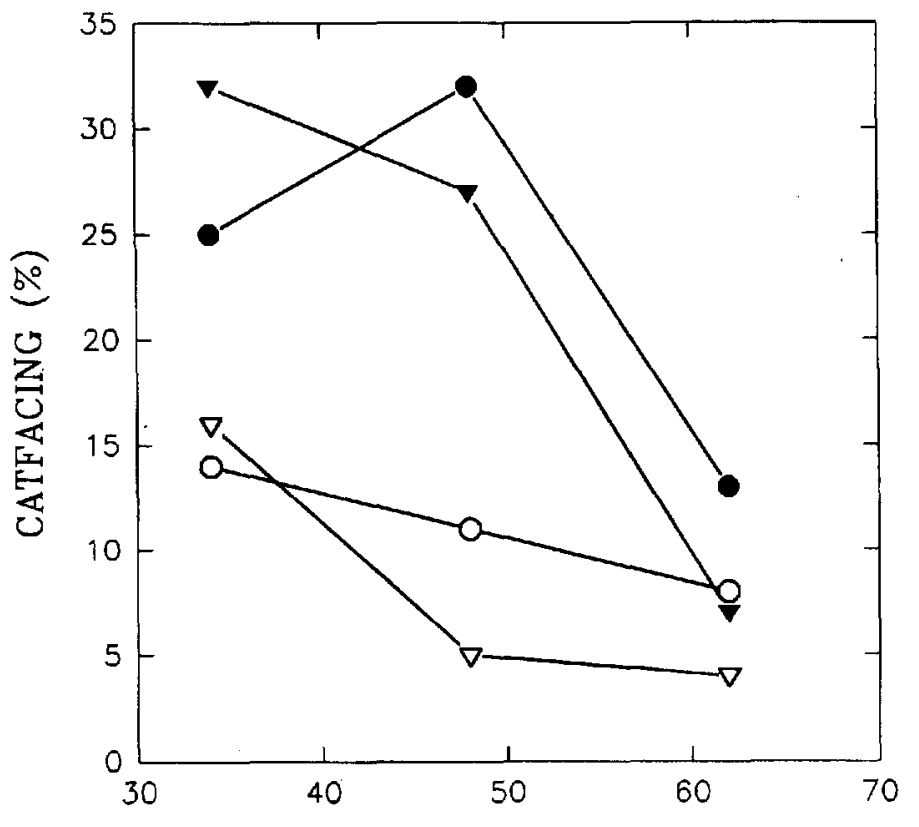

$\begin{array}{ll}\text { AGE AT TRANSPLANTING, DAYS } \\ \text { - 1989, CONTROL } & \nabla \text { 1990, CONTROL } \\ \text { - 1989, GA-TREATED } & \nabla \text { 1990,GA-TREATED }\end{array}$

Fig. 2. Catfacing percentage after tomato transplants of three ages were treated with two gibberellic acid $\left(\mathrm{GA}_{3}\right)$ concentrations at transplanting. In both years, the effects of $\mathrm{GA}_{3}$ and transplant age were significant at $P \leq 0.001$ and the interaction was significant at $\mathrm{P} \leq 0.01$. Statistical analysis was done on the arcsin-transformed variable.

for those harvested over a longer period than the 7 weeks of the present study, the sensitive period is probably longer.

Treatment with $\mathrm{GA}_{3}$ had no significant effect on total yield (Table 1), but lowered marketable yield in 1990. In 1989, highest total and marketable yields were produced by the youngest transplants in spite of increased catfacing. In 1990, total and marketable yields were highest from medium-aged transplants. Cool weather conditions in Fall 1990 prevented the yield potential of the youngest plants from being expressed. In both years, the oldest transplants exhibited the least vegetative growth and, consequently, had low yields. This characteristic is frequently noted in determinate tomato cultivars grown in cool environments (Nicklow and Minges, 1962).

Fruit weight was $32 \%$ and $10 \%$ greater for catfaced than for marketable fruit in 1989 and 1990, respectively (Table 1). GA treatment further increased weight of catfaced fruit only in 1990 but decreased weight of marketable fruit. As a result, the weight of all fruit averaged together was not significantly different between $\mathrm{GA}_{3}$ treatments. Age at transplanting had no effect on fruit weight in 1989, but was the main yield determinant in 1990. Number of fruit per hectare was not different among transplant ages in that year (data not shown).

The increased weight of catfaced fruit may have been a consequence of an increased number of locules per fruit. Treatment with $\mathrm{GA}_{3}$ has also been shown to cause locule proliferation (Hosoki et al., 1990; Sawhney and Greyson, 197 1; Wien and Zhang, 1991). It is not clear if inducing more locules to form in the developing ovary leads to fascination of the style and enlargement of the blossom-end scar. Although locule numbers and scar ratios were positively correlated in the catface-induction experiment $(\mathrm{y}=$ $0.027 \mathrm{x}-0.137, r=0.90$ at $\mathrm{P} \leq 0.01, \mathrm{n}=21$ ), such a correlation need not imply a causal relationship. It may be that low temperatures

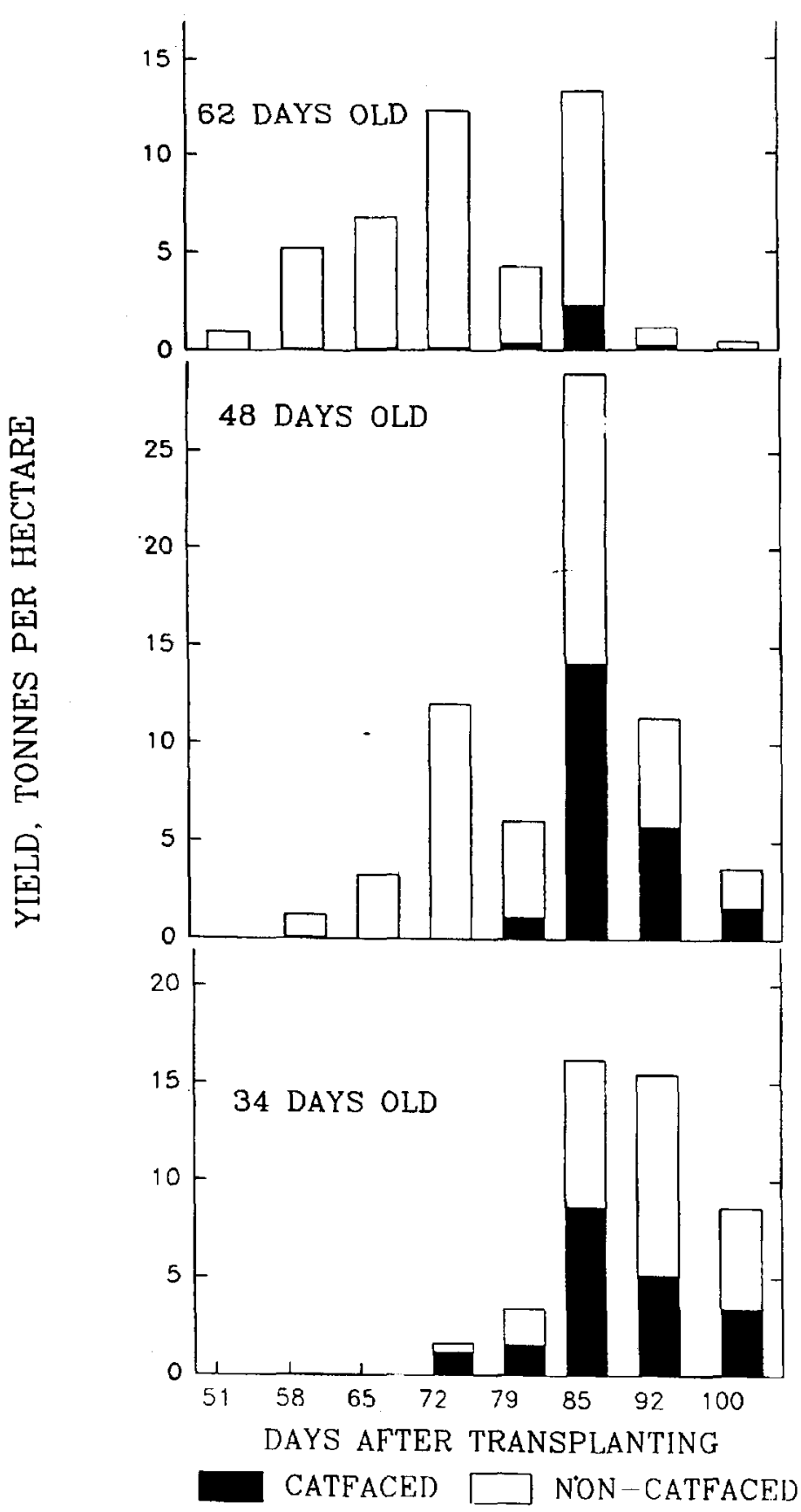

Fig. 3. Influence of plant age at time of gibberellic acid application on yields of catfaced and noncatfaced fruit in weekly harvests in the 1990 transplant-age experiment.

induced locule proliferation and stylar fascination independently. The fact that locule proliferation seems to follow the enlargement of the blossom-end scar (Fig. 1) supports this view. In a detailed time course study, Barten et al. (1992) also found no relationship between increased locule number and increased scarring. Detailed anatomical work is needed to elucidate the process of blossom-end scarring.

It is doubtful if using old transplants will be a practical way of avoiding a high incidence of catfacing in cool weather. Raising tomato plants for 9 weeks in large pots and with ample space would be prohibitively expensive in commercial enterprises. Unless optimum conditions for growth exist in the field, these fruit-bearing plants would be subject to growth checks detrimental to yield and fruit quality. It maybe possible to combine the use of medium-aged 
Table 1. Total and marketable yields and size of marketable and catfaced fruit as influenced by applying gibberellic acid $\left(\mathrm{GA}_{3}\right)$ to transplants of three ages.

\begin{tabular}{|c|c|c|c|c|c|c|c|c|c|c|}
\hline \multirow[b]{3}{*}{ Treatment } & \multicolumn{4}{|c|}{ Yield (t-ha- $\left.{ }^{-1}\right)$} & \multicolumn{6}{|c|}{ Wt/fruit (g) } \\
\hline & \multicolumn{2}{|c|}{ Total } & \multicolumn{2}{|c|}{ Marketable } & \multicolumn{2}{|c|}{ Marketable } & \multicolumn{2}{|c|}{ Catfaced } & \multicolumn{2}{|c|}{ Total } \\
\hline & 1989 & 1990 & 1989 & 1990 & 1989 & 1990 & 1989 & 1990 & 1989 & 1990 \\
\hline \multicolumn{11}{|l|}{$\overline{\mathrm{GA}_{3}}$} \\
\hline $0 \mathrm{ppm}$ & 61 & 56 & 46 & 46 & 143 & 195 & 181 & 178 & 142 & 191 \\
\hline $15 \mathrm{ppm}$ & 69 & 55 & 42 & 33 & 130 & 175 & 180 & 230 & 138 & 187 \\
\hline Significance & NS & NS & NS & $* *$ & $* * *$ & $* *$ & NS & $*$ & NS & NS \\
\hline Plant age, 62 days & $56 \mathrm{a}^{\mathrm{z}}$ & $47 \mathrm{a}$ & $41 \mathrm{a}$ & $38 \mathrm{a}$ & 137 & $175 \mathrm{a}$ & 178 & 176 & 138 & $170 \mathrm{a}$ \\
\hline Plant age, 48 days & $64 b$ & $66 \mathrm{~b}$ & $40 a$ & $47 \mathrm{~b}$ & 138 & $212 b$ & 191 & 223 & 145 & $215 b$ \\
\hline Plant age, 34 days & $73 \mathrm{c}$ & $53 a$ & $52 \mathrm{~b}$ & $34 \mathrm{a}$ & 135 & $169 \mathrm{a}$ & 171 & 212 & 137 & $182 \mathrm{a}$ \\
\hline Significance & $* *$ & $*$ & $* * *$ & $*$ & NS & $* * *$ & NS & NS & NS & $* * *$ \\
\hline
\end{tabular}

${ }^{\mathrm{z}}$ Mean separation within columns by Duncan's multiple range test at $P \leq 0.05$

Ns,******* Nonsignificant or significant at $P \leq 0.05,0.01$, or 0.001 , respectively.

transplants with a slightly later transplanting date to reduce catfacing some. Fortunately, there are sufficient differences among cultivars in catfacing susceptibility to make selection for resistance possible (Elkind et al., 1990).

\section{Literature Cited}

Barten, J. H. M., J.W. Scott, N. Kedar, and Y. Elkind. 1992. Low temperatures induce rough blossom-end scarring of tomato fruit during early flower development. J. Amer. Soc. Hort. Sci. 117:298-303.

Elkind, Y., O.B.O. Galper, S. Vidavski, J.W. Scott, and N. Kedar. 1990. Genetic variation and heritability of blossom-end scar size in tomato. Euphytica 50:241-248.
Hosoki, T., K. Ohta, and T. Asahira. 1990. Cultivar differences in fruit malformation in tomato and its relationship with nutrient and hormone levels in shoot apices. J. Jpn. Soc. Hort. Sci. 58:971-976.

Nicklow, C.W. and P.A. Minges. 1962. Plant growing factors influencing field performance of the Fireball tomato variety. Proc. Amer. Soc. Hort. Sci. 81 :443-450.

Saito, T. and H. Ito. 1971. Studies on the growth and fruiting in the tomato. XI. Effect of temperature on the development of flower, especially that of the ovary and its locule (in Japanese, with English summary). J. Jpn. Soc. Hort. Sci. 40: 128-138.

Sawhney, V.K. and R.I. Greyson. 1971. Induction of multilocular ovary in tomato by gibberellic acid. J. Amer. Soc. Hort. Sci. 96:196-198.

Wien H.C. and Y. Zhang. 1991. Gibberrellic acid foliar sprays show promise as screening tool for tomato fruit catfacing. HortScience 26:583-585. 